\title{
Literature of Acquisitions in Review, 2010-11
}

\author{
Paul D. Moeller
}

This review covers the literature of acquisitions from 2010 through 2011. This period was punctuated by continuing economic challenge, and the themes expressed in the literature are largely related to this situation. Libraries moved with conviction toward patron-driven acquisitions. The reexamination of the Big Deal persisted as libraries felt the strain of budget cuts. Approval plans continued to evolve and e-books steadily increased market share. Workflows and management tools became more sophisticated as librarians and vendors sought to cope efficiently with the influx of electronic resources.

This review of acquisitions literature is a continuation of the literature reviews 1 conducted by Dunham and Davis for the years 1996-2003 and 2004-7, and by Harrel for 2008-9, published in Library Resources and Technical Services. ${ }^{1}$ The challenges brought forth by the Internet and technological change were a major focus of the 1996-2003 review. In the 2004-7 review, prominent topics included budget concerns and the management of electronic resources. These topics continued to be a concern for the 2008-9 review as were approval plans, creating workflows, the Big Deal (the acquisition of large collections of electronic resources from individual publishers that usually include all-inclusive title lists with agreed-upon limits to price increases), the changing landscape of the marketplace, and the increasing prevalence of e-books. For 2010-11, tight budgets influenced much of the conversation. The Big Deal faced continued scrutiny. The challenges of managing e-resources led to the refinement of workflows and tools. Approval plans continued to evolve and open access publishing gained increasing momentum. Electronic books became a hit with the public and libraries alike and patron-driven acquisitions was widely discussed in the literature.

Paul D. Moeller (paulmoeller@colorado .edu) is Head of Serials and Digital Access, University of Colorado Boulder Libraries, Boulder, Colorado.

Submitted June 14, 2012; tentatively accepted July 2, 2012, pending modest revision; revision submitted August 26, 2012, and accepted for publication.

The author offers his thanks to Library Resources and Technical Services for the award of an American Library Association Carnegie Whitney grant and a special thank-you to research assistant Amy Clausen for her assistance in preparing this review.

\section{Research Method}

In identifying the significant literature published in 2010 and 2011, the author searched Library and Information Science Abstracts (LISA); Library, Information Science \& Technology Abstracts with Full Text (LISTA); and ISI Web of Knowledge for appropriate works. Using "acquisitions" and "library" as keywords and limiting by date of publication and scholarly journal, LISA returned 555 results and LISTA returned 547 results. With a similar search, ISI Web 
of Knowledge returned 221 results. The author consulted WorldCat to find monographs focused on the topic. Finally, the author conducted a systematic review of the contents of selected library science journals. Most items considered for this paper were peer-reviewed articles from scholarly journals published in English, but books, proceedings, and reports also were considered. Works on serials largely were excluded because they are covered in serials and continuing resources literature reviews. The author selected items for this literature review that were indicative of prominent themes in the literature.

The literature published in 2010 and 2011 spans various topics. For convenience, the author has organized the review into four categories (library acquisitions services, tools and resources used in acquisitions work, purchasing models, and open access). Some categories have subsections.

\section{Library Acquisitions Services}

In summarizing the findings of a survey of Association of Research Libraries' (ARL) budgets, Lowry found that

member libraries have experienced three unprecedented years of flat or reduced budgets beginning with FY 2008-09, when 55 percent indicated reduced budgets. In FY 2009-10 that trend continued, with 61 percent experiencing flat or reduce budgets from the prior year. For this year, 2010-11, 47 percent are faced with flat or reduced budgets. As observed earlier, this is the new norm and not an aberration. It will have consequences for teaching and research within higher education and in the market place of scholarly communications internationally. ${ }^{2}$

The economic downturn hit public libraries as well. According to Kelley,

the overall trend in FY10 was a brutal grasping by money-starved government officials for the low-hanging fruit of library budgets: 72 percent of survey respondents said their budget had been cut, and 43 percent had staff cuts. Among libraries serving populations above one million, these figures were even more acute, with 86 percent reporting budget cuts in their libraries and 93 percent reducing staff. They also reported a drop in service hours that on average equaled two branch closings. ${ }^{3}$

This challenging budget situation and the increase in electronic resources managed by libraries have had a continuing impact on the work of acquisitions. Attempts to manage resources more effectively and efficiently are reflected in the literature. In recent years, a number of new library positions have been created to take on responsibilities associated with managing electronic resources. Electronic resources librarians, licensing librarians, and digital collections librarians are normally responsible for acquiring electronic resources, troubleshooting access issues, and training users of the resources. Pomerantz, in an attempt to clarify whether a consensus exists on what aspects of electronic resources management are acquisitions responsibilities, developed a survey investigating the role of acquisitions librarians in electronic resources management. ${ }^{4}$ The survey results showed a significant amount of variation in responsibilities and practices. Respondents reported having from sole to widely shared responsibility for negotiations, licensing, registration, activation, and maintenance. While Pomerantz claimed no consensus for the role of the acquisitions librarian in managing electronic resources, the survey revealed perceived needs for additional training, more collaboration between departments, the development of best practices for acquisitions of electronic resources, and the need for individuals to take the initiative to learn new skills.

Traditional print workflows also were studied closely in an effort to find even marginal cost savings. Schroeder and Howland conducted a time-task study to determine the cost and processing time for shelf-ready and non-shelf-ready books. ${ }^{5}$ They conducted this study intending to find out if they should expand the acquisition of shelf-ready books. To determine the cost of cataloging and physically processing print books at the item level, they used slips placed in books on which staff noted the date and amount of time they spent working on an item and when they sent it on to the next step in processing. This process was used for shelf-ready books, partially shelf-ready books, and non-shelf-ready books, and the books were tracked until they were in the stacks ready for patron use. The study showed that shelf-ready books were 5.7 percent cheaper to process than non-shelf-ready books. Furthermore, the shelf-ready books made it to the shelves thirty-three days sooner and required 47 percent less processing time than books processed in-house.

Stouthuysen and colleagues discussed how "timedriven activity-based costing" (TDABC) can be used to develop cost models for acquisition processes. ${ }^{6}$ In their study, they worked with print materials and considered ordering, receiving, paying, and using the integrated library system (ILS) and online vendor databases in an acquisitions workflow. The authors reviewed the theoretical background of TDABC and employed this technique to determine the minimum and maximum cost for acquisition functions. The TDABC analysis provided library management with enough insight into cost drivers to enable them to make changes in software and workflows. In doing so, they provided a model for doing this sort of analysis for similar processes in other libraries. 
In another attempt to save money, Mosbo and Ballestro investigated the use of secondary and used-book sources to purchase books. ${ }^{7}$ In doing this study, they considered cost, added workflow for acquisitions staff, and potential additional work for the preservation unit. The library selected a random sample of 200 titles and ordered them from vendors on Amazon, ABEBooks, Alibris, and Biblio, all of which had high approval ratings and fulfillment rates. They purchased only books with conditions rated as "very good" or better. The authors compared the purchase and shipping costs for these titles to the list price and to what the cost would have been had the titles been firm ordered from their approval vendor. Of the 200 items purchased, the condition of twelve met the criteria for review by the preservation unit on receipt. Seven of these received minor treatment. After figuring in the cost for the preservation treatments and the small amount of extra staff time required to purchase the items from the secondary market, the library's costs were $\$ 3,639.29$ less than if they had paid the list price. The authors concluded that purchasing books from the secondary market can save money but conceded that services provided by their primary book vendor, such as the ability to download bibliographic records and invoices directly into an ILS, would offset some of the savings.

Opportunities also exist for streamlining the acquisition of digital materials. Horava noted that the growth in spending on electronic resources has had a major impact on workflows that had been geared toward acquisition of print materials. ${ }^{8}$ Print materials, while still important to some fields, now compete with electronic materials that have been incorporated into new workflows. Libraries must negotiate multiple pricing considerations for digital materials. These include subscription, firm order, annual access fees, and cataloging record fees. The prevalence of consortial purchasing only increases this complexity because this sort of activity comes with less control over content and the need to agree on pricing and cost-sharing models. In this environment, the importance of licensing is emphasized. User rights, library responsibilities, vendor responsibilities, legal boilerplate issues, perpetual access, preservation arrangements, and post-cancellation rights need to be considered. Negotiating skills have become critical because protections afforded libraries by copyright legislation in the print world do not automatically extend to electronic content. Rather, these rights must be specifically secured in licensing agreements. To free resources to take on this new responsibility, the work of acquisitions going forward will include taking full advantage of processes and collaborations with vendors and publishers so that materials are acquired efficiently and staff are assigned to duties for which automated processes are not suitable.

Lamoureux and Stemper reviewed developments in licensing trends and advocated for greater uniformity and clarity in licensing terms and conditions. ${ }^{9}$ As research libraries move to online-only subscriptions, the need for securing the right to conduct interlibrary loan (ILL) has increased. Publishers and librarians negotiating terms need to understand ILL workflow, and tools and licensing terms should replicate best practices established for print.

As decreasing library budgets inevitably affect library suppliers as well as libraries, Williams and Downes discussed the need for libraries to assess the financial health of their vendors and suggested methods for monitoring vendors' viability. ${ }^{10}$ Good stewardship demands libraries pay attention to their vendor's financial health throughout the working relationship. Bankruptcies, mergers, vendor restructuring, and even high staff turnover can pose risks to libraries. One step that libraries can take to protect themselves from these risks is monitoring the health of critical vendors. By gathering information about a vendor's financial health and recording it in a fashion that allows for easy tracking over time, a library may notice if a company is having trouble and take appropriate measures. This is timely advice because Powell reported that 60 percent of publishers indicate that the economic downturn had a negative impact on their business for 2009 and only strong sales outside of North America had kept EBSCO's worldwide sales revenue through February 2010 relatively flat—down only 0.5 percent. $^{11}$

The transition from print to electronic collections is still a topic that garners attention. Bock and Burgos-Mira wrote about the challenges faced by multi-campus environments during this transition. ${ }^{12}$ They described the evolution of a cooperative and collaborative environment in the libraries, the introduction of university-wide library committees, and the holding of retreats at various campus locations to manage the acquisitions of electronic resources.

Electronic resources are becoming increasingly common in the developing world as well. Pilgrim and Dolabaille discussed the challenges the University of the West Indies' Alma Jordan Library faces in managing the transition to electronic resources. ${ }^{13}$ Staff training, revision of the organizational structure, and reallocation of the budget are ongoing. Inadequate funding, varying levels of technological infrastructure, and small user populations on islands have slowed the development of an organized consortium, but steps have been taken to cooperate in acquiring databases. The Alma Jordan Library intends to form an electronic resources management team, develop an electronic resources policy, and possibly purchase an electronic resources management system to meet the challenges of managing electronic resources.

Anyone seeking a good overview of acquisitions may want to consult a new edition of Introduction to Technical Services by Evans, Intner, and Weihs. ${ }^{14}$ The chapter on acquisitions reviews the relationship between collection 
development and acquisitions; discusses general procedures for verification, ordering, and reporting; explains acquisitions methods from firm and standing orders to subscriptions and blanket orders; and examines the pros and cons of gifts. Holden's Acquisitions in the New Information Universe: Core Competencies and Ethical Practices is another good source for a thorough discussion of acquisitions. ${ }^{15}$ This work covers traditional acquisitions concepts of ordering, receiving, licensing, and workflow and emphasizes how they fit within access and service.

\section{Tools and Resources Used in Acquisitions Work Electronic Resource Management Systems}

The ongoing challenge of managing electronic resources continues to garner the attention of librarians and vendors. Hartnett and colleagues described their experiences with attempting to implement two electronic resource management systems (ERMS). ${ }^{16}$ These attempts were made with the goal of locating and managing the information found in knowledge bases, order records, networked folders, spreadsheets, file cabinets, and collective memory in an ERMS. They first worked with the ERMS offered by their ILS vendor. They had hoped that this ERMS would allow them to manage workflows and to improve communication of information to staff and users. During set up of this ERMS, they determined that the product was unintuitive in several areas ranging from terminology to workflows. Some features did not work or did not work well, and some promised features were never developed. Eventually, they moved to another ERMS. Although this product was less complex to set up, they still found that it did not work with resources that included e-journals and e-books and did not integrate with other products. Thus it could not pull financial information from the ILS or statistics from vendors. The link resolver also could not sync with another vendor's knowledgebase. When looking for an ERMS, these authors recommended compiling a list of the most pressing needs and finding a system that addresses them.

Silton and LeMaistre conducted a survey of users of Innovative Interfaces' ERMS, attempting to determine satisfaction with implementation, impact on workflow, and impact on patrons. ${ }^{17}$ Respondents indicated some dissatisfaction with implementation and the impact on staff workflows. However, the survey did show some positive effects that coverage load and license information display had on patron access.

Collins and Grogg surveyed librarians and ERMS vendors in an attempt to develop a clear understanding of the state of ERMS. ${ }^{18}$ The surveys showed that librarians were most concerned with ERMS' ability to manage workflow, licensing, and statistics; store administrative information; provide support for acquisition functions; and interoperate across systems including the ILS. The surveys revealed a high level of satisfaction with license management, although respondents expressed concern with displays in nextgeneration discovery layers. Statistics management also proved to be problematic because ERMS failed to implement the Standardized Usage Statistics Harvesting Initiative (SUSHI) standard. SUSHI is a National Information Standards Organization (NISO) standard that describes the automated harvesting of statistics through a web service. A common element of many of the shortcomings of ERMS is lack of interoperability. Lack of interoperability affects the ability to determine cost-per-use or to gather cost and vendor information from the ILS. The key to ERMS working better with other systems is developing standards and putting them to use.

Whitfield noted that expense and lack of interoperability have been factors in libraries deciding not to implement ERMS.$^{19}$ To overcome these problems, some libraries have chosen to work with the open-source ERMS Centralized Online Resources Acquisitions and Licensing (CORAL) (http://erm.library.nd.edu). Developed by the University of Notre Dame's Hesburgh Libraries, CORAL is built using PHP 5 and MySQL technology and consists of acquisitions, licensing, contacts, statistics, and cancellation modules from which libraries can choose when deciding how to manage their resources. Whitfield was only using CORAL as a desktop application, yet it allowed for more efficient management of electronic resources.

Gustafson-Sundell did a careful review of the marketplace and a detailed assessment of the local situation at the Northwestern University Library (NUL) before deciding to implement CORAL's licensing module. ${ }^{20}$ The decision to go only with the licensing module was based on a degree of satisfaction with the effectiveness of the SFX link resolver, A-Z lists, and MARC records service already in use at NUL and a reluctance to take on the expense in funding and staff time to implement a full-fledged ERMS. Gustafson-Sundell stated that libraries should carefully consider tools already in place, prior commitments of staff, and other local conditions before deciding to implement an ERMS. Milczarski and Garofalo also described conducting a needs assessment and a review of the marketplace before deciding to implement True Serials. ${ }^{21}$ True Serials is a hosted ERMS that is powered by the open-source CUFTS solutions (http:// researcher.sfu.ca/cufts) from Simon Fraser University. This option offered the integrated $\mathrm{A}-\mathrm{Z}$ database and a link resolver with a small financial burden.

\section{Standards}

Librarians, vendors, and publishers who work with e-resources need to follow the development of standards 
that affect their work. Pesch offered a summary of current and developing standards that are useful for acquisitions, collection assessment, and access, and he explained why they matter. ${ }^{22}$ Counting Online Usage of Networked Electronic Resources (COUNTER) and SUSHI together allow for automated harvesting of meaningful usage data for databases, e-journals, and e-books. Journal Usage Factor, EigenFactor, and Metrics from Scholarly Usage of Resources (MESUR) offer alternative means of assessing scholarly impact factors. Shared E-Resource Understanding (SERU) proposes an alternative to signed license agreements that set expectations on the use of content and the responsibilities of libraries and publishers. Knowledge Bases and Related Tools (KBART) and Improving OpenURLs Through Analytics (IOTA) advance linking by improving the accuracy of data in the knowledge base and the quality of data in the OpenURL. Establishing Suggested Practices Regarding Single Sign-On (ESPReSSO) will allow for greater effectiveness of single sign on authentication systems. I ${ }^{2}$ (Institutional Identifiers) would create standard identifiers for institutions and make transfers and transitions easier and the gathering of data more efficient.

Carpenter discussed the status of National Information Standards Organization (NISO) standards affecting electronic resources management and explained why some standards have gained wider adoption than others. ${ }^{23} \mathrm{He}$ noted that the SUSHI Protocol has been successful and he attributed that success to "the pervasiveness of the problem that it addresses, tying compliance to existing end-user expectations, the relative simplicity of its implementation, and the ongoing support and education that is provided surrounding the standard." ${ }^{24}$ Carpenter urged that focus be placed on projects that are likely to have broad adaption, where savings are great, and that will be easy to implement. These are the projects that will be most productive, will have the greatest impact on the distribution of content, and will be of the greatest benefit to publishers, libraries, and users.

\section{Additional Tools}

Many tools in addition to ERMS have been applied to getting the work of acquisitions done. Some offer variations of established practices while others apply tools that were not developed for libraries. Shapiro described using Google Calendar at Montclair State University to expedite the handling of renewals, monitor the beginning and end of database trials, and track scheduled meetings with vendors. ${ }^{25}$ Shapiro found Google Calendar easy to use and effective.

Leffler and Zuniga, in an attempt to reduce time spent by the University of Northern Colorado Libraries' staff inputting license terms into a newly purchased ERMS, used Microsoft Excel to develop a form to record license data. ${ }^{26}$ Staff reviewed license agreements and filled out the Form for License Details (FFLD) before installation of the ERMS. Information input in the FFLD included start and end dates, electronic reserves, course packs, ILL, and access terms. The use of this form gathered critical information from license agreements in a normalized and easily accessed manner. Leffler and Zuniga found that the form streamlined the entering of licensing information into the ERMS and suggested that it would be useful for any library maintaining licensing agreements for electronic resources. England, Fu, and Miller took a similar approach at University of Maryland University College Library to improving management of e-resources. ${ }^{27}$ They used checklists to limit mistakes, reduce complexity, and ensure that work on e-resources was done effectively. Pan, Bradbeer, and Jurries of the University of Colorado Denver Auraria Library described using a blog as a centralized management tool to track e-resources issues. ${ }^{28}$ The blog posts included a description of a problem, assigned troubleshooting to an appropriate person, set the priority and status, and allowed space for notes. The blog enabled the authors to capture, organize, and easily access troubleshooting information. An offshoot of the use of the blog was the creation of a community of practice among the authors. This community was a self-formed group of peers that utilized complementary skills to respond to e-resources access problems in which leader and follower roles shifted between the participants depending on the circumstances of particular problems.

Wilson reported on three libraries using web-based software not designed for the library market to manage e-resources acquisitions and workflows. ${ }^{29}$ JIRA (www.atlassian.com/software/jira), a task and problem tracking software is being used to track the work and staff involved in managing e-resources from ordering to metadata provision. Drupal, a content management system that allows users to create and manage websites, is being used to create a tool that tracks workflow, stores data, and manages public access to databases and journal collections. Basecamp, an online project management tool, is being used to support acquisitions and workflow. Usability, the ability to customize, and having a single, easily accessed place for collocating the information important for managing e-resources, are reasons cited for utilizing these tools. Understanding processes and taking advantage of software already available to a campus or library are highly recommended.

Librarians often take the work of managing e-resources with them as they attend conferences or are away from the office for other reasons. Hartnett and Price tested the potential of Apple's iPad as a mobile management tool..$^{30}$ They reviewed the tasks addressed in their work and investigated the availability of apps that would enable the iPad to do this work. While they found the iPad's size, the availability of both Wi-Fi and 3G service, and its intuitive interface 
advantageous, they concluded that problems with printing, file management, and working directly with a server limited the iPad's effectiveness. The development of streamlined library apps may make the iPad a more useful mobile tool for librarians.

Bindle and Boden explored the potential benefits of using digital photography for evaluating prospective gift-inkind donations. ${ }^{31}$ They described a method for using readily available equipment, such as a compact point-and-shoot digital camera and a tripod with an invertible center column, to create digital images of each item in a potential donation. These images could then be used in an assessment of the potential gift, shared with appropriate parties, and used to promote the discovery and use of the gift.

\section{Purchasing Models Approval Plans and Standing Orders}

In this prolonged period of economic challenge, libraries are looking for means of increasing efficiency and effectiveness. Approval plans are not immune to scrutiny. Alan and colleagues conducted a study designed to evaluate the monograph approval plan profiles at Penn State and the University of Illinois Urbana-Champaign (UIUC) for use, cost effectiveness, and coverage. ${ }^{32}$ The goals of the study were to develop benchmarks for evaluating the effectiveness of an approval plan profile and develop a reproducible method with baseline data that would allow other libraries to collect data and conduct their own studies. The study collected one fiscal year of approval plan purchasing data and up to thirty-three months of circulation use data. The results of the study showed that 41 percent of the monographs received on approval by Penn State overlapped with those received on approval by UIUC, and 51 percent of the items received on approval at UIUC overlapped those received by Penn State. The lower amount of overlap for Penn State is likely due to the larger number of titles it acquired on approval. The study also revealed that 31 percent of Penn State's approval plan receipts and 40 percent of UIUC's approval plan receipts did not circulate during the study period; that the average cost per use was $\$ 19.83$ for Penn State and $\$ 22.28$ for UIUC; and that the average circulations per title was 2.85 for Penn State and 1.73 for UIUC. This study set a benchmark that these and other libraries can use to evaluate attempts to make approval plans more efficient and to ensure that they are serving the needs of their institutions.

Brantley took a different approach to evaluating approval plans. ${ }^{33}$ He assumed that books reviewed in the highly regarded review journal, American Historical Review, should be in academic library collections due to the attention given them by the journal. In reviewing the holdings of twenty-one members of the ARL, Brantley found that books from small publishers or those classed outside of disciplinary boundaries are frequently missed in the approval process. This demonstrated that, while approval plans can be efficient, they require expert oversight to ensure they deliver the full range of quality titles.

Buckley and Tritt discussed how they introduced e-books into their monograph approval plan to increase the number of e-books available for academic programs with large numbers of off-campus students. ${ }^{34}$ Working with their vendor, they determined subject and nonsubject parameters and set a three-month delay on delivery of print versions of titles to allow time for the e-version to be released. E-books titles that matched a profile were made available for online review and selectors were able to accept, reject, or defer each title. The vendor supplied MARC records with invoice data for the accepted e-books and these records were added to the library's catalog. Buckley and Tritt cautioned that e-book approval plans are subject to decisions, such as the delay between the release of print and digital version of titles, made by publishers that affect the functionality of the approval plan, but they considered the inclusion of e-books in their approval plan to be successful.

Fong and colleagues from the Colorado Alliance of Research Libraries experimented with a collaborative approach to managing duplication of print monograph holdings across a consortium using coordinated approval plans. ${ }^{35}$ Working with eight libraries, two book vendors, and four subject areas, they attempted to build a process that would control duplication of core undergraduate titles, build stronger overall collections, free selector time, and free funds for the purchase of unique materials. While the pilot did not effectively reduce duplication, save selector time, or save money, the pilot did push selectors and technical services librarians to develop new procedures and to work more collaboratively across the consortium. It also helped to build a culture of cooperation and experimentation between and within the participating libraries.

Handman discussed evolving models for delivery of educational and documentary video content online ${ }^{36}$ Increasing user expectations for remote access, the need to replace deteriorating collections of video on obsolete media, the integration of learning management systems in educational programs, and the increased emphasis on providing services for remote and disabled patrons has increased the demand for video on demand (VOD). Handman reviewed VOD delivery modes and licensing models and concluded that none of the models serves the broad scope of institutional needs. Libraries will continue to build collections of videos while experimenting with just-in-time models.

Cross maintained that, in a time when libraries no longer strive for completeness, the need for standing orders has diminished. ${ }^{37}$ Standing orders usually are established 
to ensure that a multivolume series will be held by a library free of any missing volumes. These irregularly published books can be overlooked when reviewing monograph expenditures because they are usually purchased with serials funds and are overlooked in reviews of serials expenditures because they are not journals and do not increase in price at a rate that raises flags. Thus they can arrive in a library for years without review for appropriateness of coverage or price effectiveness. Cross suggested that acquisitions and collection development personnel gather the ongoing standing orders in a spreadsheet for evaluation. Obsolete titles or series that no longer meet the needs of the institution should be cancelled. Other titles may be moved to approval plans. Taking these items out of the serials flow imposes structure on a grey area of the collection budget, clears items from active titles lists, and allows for future assessments of a collection to be done more efficiently.

\section{E-Books}

Interest in e-books continues at a high level with vendors and publishers attempting to develop sustainable business models, and libraries experimenting with means of getting these books to their users. While e-book availability has expanded in recent years, issues have hindered their adoption by libraries and users. Slater identified a number of such issues. ${ }^{38}$ These included a continuing reluctance on the part of many patrons to use e-books. These patrons find the mechanisms for discovering and accessing e-books bought and licensed by a library to be more problematic than accessing freely available e-books through the web. When patrons have successfully accessed a title, they are frustrated by the limitations placed on printing, downloading, and repurposing the content by digital rights management (DRM) restrictions. Furthermore, many scholarly titles still are not available as e-books. The challenges associated with licensing, preserving, and acquiring e-books remain more prevalent than they do for the print counterparts.

Many libraries are purchasing e-book collections directly from publishers because these collections can be DRMfree, and print-on-demand options are available for patrons. Bucknell reviewed the COUNTER usage reports for one such collection and found that this approach was working well because use was good across most subjects, the number of unused titles diminished each year, older titles continued to be used, and the cost-per-use was relatively low. ${ }^{39}$

Other libraries have tried this approach and found it problematic. Schroeder and Wright reviewed their experience with leased collections such as those offered by ebrary and Safari and found that only 20-35 percent of the titles in the collections were being used. ${ }^{40}$ They also noted that while the publishers' frontlists and backfile collections offer libraries the option of purchasing many books easily, the purchase of these sorts of collections may not be sustainable for libraries with shrinking budgets. They advocated the use of patron-driven models that integrate e-books with print approval profiles.

Those looking for a thorough treatment of e-books may want to consult No Shelf Required: E-Books in Libraries, edited by Sue Polanka. ${ }^{41}$ This work offers chapters on the evolution of e-books; their use in public, school, and academic libraries; an examination of the process of purchasing e-books including business models, licensing, workflow processes, cataloging, and management; usage; and standards including EPUB (an open e-book standard designed to optimize text for display devices), DRM, the International Standard Text Code (ISTC; a numbering system providing unique identifiers for text-based works), and SERU. In a more concise treatment of these issues, Polanka offered a quick explanation of business models; discussed the challenges and advantages of purchasing from publishers, aggregators, or wholesalers; and described the benefits and difficulties of purchasing as part of a consortium. ${ }^{42}$ She recommended that libraries evaluate vendors with whom they are considering working for content, price, DRM restrictions, availability of MARC records, licensing terms, and other features. Most importantly she stressed the need for libraries to understand their primary goals for purchasing e-books.

\section{Just-in-Time Models}

Whether it is referred to as patron-driven acquisitions (PDA), purchase-on-demand, patron-initiated purchasing, or demand-driven selection, just-in-time purchasing has received a good deal of attention as libraries attempt to meet the needs of patrons while limited by distressed budgets. Several articles evaluated initiatives to purchase books and similar items requested through ILL. Tyler and colleagues conducted a very thorough evaluation of a fiveyear trial of a small purchase-on-demand program based on ILL requests at the University of Nebraska-Lincoln Libraries. ${ }^{43}$ Their evaluation showed that the selected items were suitable for the library and fell within high-use Library of Congress classification subclasses. These items also circulated at a higher rate and had elevated amounts of repeat circulation when compared to those purchased through traditional channels.

In a three-part series, Purdue University librarians evaluated a decade of patron-driven collection development. ${ }^{44}$ Anderson and colleagues analyzed the purchase of liberal arts books through the program. Criteria for purchasing ILL book requests were set initially to include only scholarly, nonfiction books in English published in the past five years with a maximum cost of $\$ 150$. Over time, the English language requirement was relaxed, the publication range was tightened to those published in the past three 
years, and requests for DVDs were included. Requests were reviewed by a staff member who decided if an item met the requirements. Analysis of the program showed that almost half of the books purchased were requested by members of liberal arts departments, the majority of the purchased materials were suitable for the collection, and many of the purchased items were cross-disciplinary in nature. In part 2 of the Purdue study, Bracke analyzed the science and technology books. ${ }^{45}$ The findings for these items were similar to those purchased for the liberal arts-the purchased items were deemed appropriate for the collection. Many of the purchased items identified emerging areas for selectors to review. Moreover, only 17 percent of the books had not circulated beyond the initial ILL request. Although Purdue heavily emphasizes science and technology, only 15 percent of items purchased via the program were in the science and technology area. In part 3 of the study, Nixon and Saunders focused on circulation of the books purchased on demand. ${ }^{46}$ Their findings showed that books purchased via ILL demand had higher circulation rates than those purchased through normal channels.

A review of an ILL PDA program at The Ohio State University done by Hodges, Preston, and Hamilton exhibited similarities. ${ }^{47}$ The general criteria used for converting ILL borrowing requests to purchases included a $\$ 200$ price limit and a publication date within the last two years. Computer manuals and popular culture materials were in general excluded as were items that could be borrowed. Textbooks were purchased for closed reserve. Graduate students were the most frequent beneficiaries of the program, and items purchased through the program averaged sixteen circulations during a twenty-two-month period.

Silva and Weible described an ILL purchase program at the University of Illinois at Urbana-Champaign that overcame problems with slow delivery of materials and an overwhelmed ILL and acquisitions staff by changing the source of potential purchases from unfilled regular ILL requests to items that could not be borrowed through a patron-initiated consortial borrowing system. ${ }^{48}$ This change removed most items that were as difficult to purchase as they were to borrow from the workflow and allowed the ILL purchase effort to provide user-selected materials in a timely way.

Hussong-Christian and Goergen-Doll used commonly accepted measures such as turnaround times and circulation rates and employed patron feedback in evaluating an Oregon State University Libraries' ILL purchase pilot. ${ }^{49}$ In this pilot, books purchased for graduate students or faculty had a printed band on them that explained the pilot. After the end of the academic session, an email message was sent to these participants with further explanation of the pilot and an invitation to provide feedback via an online survey. In the feedback, the patrons expressed high satisfaction with the pilot with many of them indicating that they would recommend the purchased items to others or put them on reading lists. Patrons unsurprisingly indicated that quick turnaround time was very important to them. HussongChristian and Goergen-Doll reported that staff from ILL and acquisitions units had worked very closely together in the pilot, they were working toward an alignment that would enhance this collaboration, and they were considering implementing the Getting It System Toolkit (GIST). GIST is a tool that merges acquisitions and ILL workflows in a single interface.

Pitcher and colleagues at the State University of New York, Geneseo, developed GIST in an attempt to integrate ILL and acquisitions workflow in one interface and to automate the integration of decision support data. ${ }^{50}$ GIST integrates with ILLiad ILL management software. It collects information from the user and pulls data from external sources. Staff using GIST can be informed of the patron's choice of format, the cost to purchase the item, and if a free version is available online.

In an attempt to quantify the extent of active ILL PDA programs in the Pacific Northwest, Fountain and Frederiksen surveyed the members of the Orbis Cascade Alliance, a consortium of thirty-six academic libraries in Washington and Oregon. ${ }^{51}$ Through the survey, the authors wanted to determine the degree of participation in ILL PDA programs and how the participants implemented the programs, and to gauge interest in ILL PDA by nonparticipating libraries. Twenty-five percent of the respondents had active programs, 16 percent were considering introducing one, and 61 percent had no plans to do so. From those libraries taking part in ILL PDA, Fountain and Frederiksen were able to document typical workflows and parameters used to determine a request's eligibility for PDA rather than traditional ILL, such as an item not being available from a local consortial vendor, the request coming from an eligible borrower, the cost of an item falling within specified limits, and an item having a recent publication date. Budgets and workflow concerns were the main reasons cited by the libraries choosing not to employ ILL PDA.

While the literature offers much in support of ILL PDA initiatives, van Dyk cautioned that librarians may be underestimating the costs associated with ILL PDA. ${ }^{52}$ According to van Dyk's analysis, an ILL PDA transaction is much more expensive than ILL borrowing costs. Therefore a $\$ 75$ purchase-on-demand item would need to circulate as many as six times to break even with traditional ILL borrowing costs. van Dyk recommended more cost studies so that libraries can make better informed purchase or borrow decisions.

Many libraries have taken just-in-time selection a step further by purchasing e-books through PDA. Johnson explained that the most important thing a library should do before investigating models is to understand what is wanted 
from this process. ${ }^{53}$ PDA can be used to reduce expenditures, to expand the availability of electronic content, as an alternative to ILL, or as a means of shifting some of the responsibilities for collection development to the patron. Once the institution's goals are clear, he recommended that subject specialists come together with technical services specialists to ensure that technical aspects (e.g., level of cataloging, integration of records, and how invoicing would work) are considered along with collection development aspects. Johnson does a good job of reviewing options offered by vendors including single, multiple and unlimited simultaneous users, pricing models, purchase triggers, ILL privileges, and licensing issues.

De Fino and Lo explored the challenges of introducing PDA to a library. ${ }^{54}$ In the model chosen by their library, a profile was created with the assistance of the vendor. The vendor then supplied records that were loaded into the catalog. As these books were discovered and used by patrons, a purchase was triggered. The vendor then sent reports of purchased items and the vendor records were replaced in the catalog with permanent full records. On a monthly basis, the vendor supplied a list of titles to be reviewed by selectors. Selectors then chose titles for inclusion in the project and the vendor then provided records for discovery.

McElroy and Hinken reviewed the steps the Orbis Cascade Alliance took in preparing to enter into a pilot consortium program for sharing e-books across member libraries. ${ }^{55}$ The Alliance considered several models for acquiring e-books for the consortium. These included a demand-driven model with purchases triggered by use, the selection of individual titles by selectors, and the purchase of subject collections. Ultimately, the Alliance decided to pilot a combination of pay-per-view and demand-driven acquisition with a set number of short-term loans triggering a purchase. McElroy and Hinken also discussed the complexities of discovery and managing processes in a consortial environment.

Price explained why the DRM agreements that aggregators have with publishers have caused him to stay away from purchasing e-books through PDA for the Claremont University Consortium. ${ }^{56} \mathrm{He}$ has instead chosen to purchase packages directly from publishers like Springer or to utilize a PDA-like Evidence Based Selection (EBS) service from Elsevier. These DRM-free collections have features such as the option to download chapters as PDF files and the ability to cut and paste graphics that patrons want. Price suggested that publishers, aggregators, and book vendors work together to develop a system for delivering DRM-free books through a PDA system.

Levine-Clark decided to move to a multiple-format demand-driven acquisitions plan for the University of Denver Penrose Library. ${ }^{57} \mathrm{He}$ continues to use an approval plan, so some print books still come to the libraries automatically.
The print titles that have been purchased through slips in the past are now to be loaded into the library's catalog providing users with a request a purchase option. Records for PDA e-books from multiple vendors will be loaded in the catalog as well. The combination of the patron order slips for print and the purchase-on-demand for e-books will allow users to choose between print and electronic versions for many titles. When use of an electronic version of a title reaches the point of a purchase, the title will appear on a monthly invoice and any record for a duplicate e-version of the title will be removed from the catalog. Requests for print titles will be queued to the acquisitions department with many of the titles being ordered immediately and more expensive ones being forwarded to selectors. LevineClark expected that this transition to demand-driven acquisition will allow for the purchase of a better selection of books with a much lower percentage of low use titles.

Jones described another move to an integrated print and electronic PDA model at the University of Arizona Libraries ${ }^{58}$ In his case, budget cuts have led to reduced staffing and acquisitions funding at the same time that users have developed an expectation that information will be available wherever and whenever they want it. In the newly developed model, the print approval plan is expected to provide only core materials that have high expectations of use or items that are within a few high-priority subject areas. The print approval plan also is expected to ship only titles not available as e-books. A ninety-day delay is built into the delivery to allow time for the digital version of a title to be published. E-books that fit the profile are loaded into the catalog and a purchase occurs when it has been used three times (in this case, use excludes views of table of contents, title page, and index). Records for print books matching the profile but not available digitally are loaded into the catalog and the items are available for order by affiliated students, faculty, and staff. Records for print titles that have not been purchased are replaced with an e-book record as the digital version becomes available. Selectors also will order reference tools, multivolume titles, and other items as needed to address any imbalance in the collection. Jones concluded with the hope that a print copy on demand feature and integration with ILL will be added over time.

An excellent source of further information about PDA is Patron Driven Acquisitions: History and Best Practices, edited by Swords. ${ }^{59}$ In this work, industry leaders explained how to utilize PDA and the implications of PDA on libraries and the publishing industry. Lugg explained how PDA is disrupting the supply chain for books. Nardini explained how approval plans work with PDA programs to control selection. Polanka and Delquié described PDA business models. Way and Garrison reported how they employ shortterm loans in their e-book PDA plan, and Dillon explained how to control cost in PDA programs. The implications 
of PDA for acquisition librarians are many. The concept of collection will continue to evolve as will the workflows, services, and tools needed to manage the new means of acquiring materials.

\section{The Big Deal}

During this prolonged period of flat or declining acquisitions budgets, the Big Deal continued to be a focus of attention. Horava noted that Big Deals offer substantial benefits, but they do so at the cost of diminished control over content and pricing. ${ }^{60}$ More flexibility in content inclusion and removal, title replacement, cancellation rights, and continuing access to subscribed materials on nonrenewal of the deal is needed. While the Big Deal approach has supporters, it has been the center of tension as libraries have had to cancel titles during economic downturns.

Bergstrom observed that many academic libraries are now entering in to a third or fourth Big Deal with major publishers. ${ }^{61}$ Annual increases for these deals have been in the 5-7 percent range, and most universities are now paying twice as much in real dollars than they were in the first year of the first contract. Libraries can refuse to renew a big deal, but they do so in an environment where publishers maintain high prices for pay-per-view and individual subscriptions to keep libraries tied to the Big Deal. Even so, some libraries have managed to do without Big Deals, choosing instead to subscribe to a limited number of titles and acquire articles from unsubscribed journals individually. Bergstrom found a marked difference in the amount libraries pay for a Big Deal. Hard bargaining has saved some libraries a great deal of money. He stressed that those involved in the negotiations should have a good understanding of the best outcome the library could achieve without the Big Deal and estimate the value of the Big Deal based upon the fallback position.

Pickett pointed out that the price libraries pay for a resource is not the only measure of its cost. ${ }^{62}$ The time acquisitions personnel spend negotiating with vendors, conducting trials, activating packages, and reviewing licenses is costly. Between 2007 and 2009, Texas A\&M University Libraries acquired eleven individually negotiated and licensed ProQuest databases, and more were likely to be added in future years. Each of these new databases required trials, negotiations, review of license by the university contracts administration, and set-up in library discovery systems. Renewals for ProQuest databases also took significant time. To reduce this expenditure of staff resources, Pickett's library negotiated a contract for all ProQuest content for a price similar to current expenditure. This price also included all new ProQuest content for the length of the five-year contract. In this way, the Big Deal business model was used to secure content at a reasonable price while reducing the costly staff expenditure that had accompanied prior arrangements.

\section{Open Access}

Librarians have long been advocates of open access and have supported open access initiatives in a variety of ways. Martin suggested that librarians become knowledgeable about open access resources and prioritize management of them. ${ }^{63}$ Linking patrons to open access materials is a valuable service, and libraries should strive to make this access seamless. Bhatt advocated utilizing a publication access management system such as Serials Solutions to provide access to as many open access collections as possible. ${ }^{64}$ Cryer and Collins suggested becoming familiar with government funding initiatives such as the National Institutes of Health Public Access Policy, participating in Open Access Week, and promoting the use of open access models by ensuring that open access journals are available through the library's catalog. ${ }^{65}$ Librarians should be knowledgeable of institutional open access funds and local policies for their use. Licensing language that supports self-archiving or archiving in an institutional repository should be made widely available. Librarians also should be familiar with open access policies and prepared to promote open access concepts through daily activities.

Hellman discussed models for open access e-books. ${ }^{66}$ For an e-book to be considered open access, intent on the part of the publisher to make it openly available with an appropriate license and effective distribution is necessary. Possible models for open access e-book publishing include do-it-yourself, public funding, crowd sourcing, and crowd funding. Once produced, open access e-books need a means of effective distribution. Hellman noted that venues for cooperation, such as Open Library and HathiTrust, already exist but suggested that others will be needed. Open access e-books have great potential, but work is needed to ensure that they are widely available.

\section{Conclusion}

The acquisitions literature review for 2010 and 2011 reveals libraries, vendors, and publishers working cooperatively and collaboratively in the face of the continuing economic downturn. Tools are being developed, refined, and repurposed to meet the needs of librarians managing electronic resources. Improving standards are easing the flow of information and improving the user experience. Approval plans are expanding to deliver e-books and print books on demand while being otherwise narrowed to only supply print books with high probability of use. Just-in-time acquisition models 
are being embraced because they show promise of more efficiency than traditional acquisition models that rely on title selection by librarians. The Big Deal and open access publishing draw praise and critical attention. Acquisitions specialists affect and react to these developments. They adjust workflows and management structures to accommodate the changing nature of their work while developing new skills that will enable them to meet coming challenges.

\section{References}

1. Barbara S. Dunham and Trisha L. Davis, "Literature of Acquisitions Review, 1996-2003," Library Resources \& Technical Services 52, no. 4 (2008): 238-53; Barbara S. Dunham and Trisha L. Davis, "Literature of Acquisitions Review, 2004-7," Library Resources \& Technical Services 53, no. 4 (2009): 231-42; Jeanne Harrell, "Literature of Acquisitions Review, 2008-9," Library Resources \& Technical Services 56, no. 1 (2012): 4-13.

2. Charles B. Lowry, "Three Years and Counting-The Economic Crisis is Still with Us," portal: Libraries of the Academy 11, no. 3 (2011): 760 .

3. Michael Kelley, "Bottoming Out?” Library Journal 136, no. 1 (2011): 28.

4. Sarah B. Pomerantz, "The Role of the Acquisitions Librarian in Electronic Resources Management," Journal of Electronic Resources Librarianship 22, no. 1/2 (2010): 40-48.

5. Rebecca Schroeder and Jared L. Howland, "Shelf-Ready: A Cost-Benefit Analysis," Library Collections, Acquisitions \& Technical Services 35, no. 4 (2011): 129-34.

6. Kristof Stouthuysen et al., "Time-Driven Activity-Based Costing for a Library Acquisition Process: A Case Study in a Belgian University," Library Collections, Acquisitions \& Technical Services 34, no. 2/3 (2010): 83-91.

7. Julie Mosbo and John Ballestro, "Buying from Secondary Markets: Acquiring Dollars and Sense," Technical Services Quarterly 28, no. 2 (2011): 121-31.

8. Tony Horava, "Challenges and Possibilities for Collection Management in a Digital Age," Library Resources \& Technical Services 54, no. 3 (2010): 142-52.

9. Seldon Durgom Lamoureux and James Stemper, "White Paper: Trends in Licensing," Research Libraries Issues no. 275 (2011): 19-24, accessed June 13, 2012, http://publications .arl.org/rli275/20.

10. Virginia Kay Williams and Kathy A. Downes, "Assessing Your Vendors' Viability," Serials Librarian 59, no. 3-4 (2010): 313-24.

11. Allen Powell, "Times of Crisis Accelerate Inevitable Change," Journal of Library Administration 51, no. 1 (2010): 105-29.

12. Julia Bock and Rosemary Burgos-Mira, "Navigating the Future: Understanding Common Tasks in a Multi-Campus Environment in the Dramatically Changing Acquisition World," Journal of Electronic Resources Librarianship 22, no. 3/4 (2010): 113-23.
13. Mariella Pilgrim and Arlene Dolabaille, "Our Journey from Print to Electronic Resources: An Acquisitions Perspective at a Caribbean Academic Library," Serials Librarian 61, no. 1 (2011): 90-104.

14. G. Edwards Evans, Sheila S. Intner, and Jean Weihs, Introduction to Technical Services, 8th ed. (Santa Barbara, CA: Libraries Unlimited, 2011).

15. Jesse Holden, Acquisitions in the New Information Universe: Core Competencies and Ethical Practices (New York: NealSchuman, 2010).

16. Eric Hartnett et al., "Opening a Can of wERMS: Texas A\&M University's Experiences in Implementing Two Electronic Resource Management Systems," Journal of Electronic Resources Librarianship 22, no. 1/2 (2010): 18-27.

17. Kate Silton and Tiffany LeMaistre, "Innovative Interfaces' Electronic Resources Management System: A Survey on the State of Implementation and Usage," Serials Review 37, no. 2 (2011): 80-86.

18. Maria Collins and Jill Grogg, "Building a Better ERMS," Library Journal 136, no. 4 (2011): 22-28.

19. Sharon Whitfield, "Implementing CORAL an Electronic Resource Management System," Computers in Libraries 31, no. 8 (2011): 18-22.

20. Gustafson-Sundell, "Think Locally: A Prudent Approach to Electronic Resource Management Systems," Journal of Electronic Resources Librarianship 23, no. 2 (2011): 126-41.

21. Vivian Milczarski and Denise A. Garofalo, "True Serials: A True Solution for Electronic Resource Management Needs in a Medium Academic Library," Journal of Electronic Resources Librarianship 23, no. 3 (2011): 242-58.

22. Oliver Pesch, "E-Resource Standards You Should Know About," Serials Librarian 61, no. 2 (2011): 215-30.

23. Todd Carpenter, "The Value of Standards in Electronic Content Distribution: Reflections on the Adoption of NISO Standards," Journal of Electronic Publishing 14, no. 1 (2011), accessed August 22, 2012, http:/quod.lib.umich .edu/j/jep/3336451.0014.102/--value-of-standards-in-electronic -content-distribution?rgn=main;view=fulltext.

24. Ibid.

25. Steve Shapiro, "Using Google Calendar as an Email Alert System for Electronic Resource Renewals," Journal of Library Innovation 1, no. 1 (2010): 52-56, accessed June 13, 2012, www.libraryinnovation.org/article/view/23/24.

26. Jennifer J. Leffler and Heidi A. Zuniga, "Development and Use of License Forms for Libraries with and without Electronic Resource Management Systems," Technical Services Quarterly 27, no. 3 (2010): 279-88.

27. Lenore England, Li Fu, and Stephen Miller, "Checklist Manifesto for Electronic Resources: Getting Ready for the Fiscal Year and Beyond," Journal of Electronic Resources Librarianship 23, no. 4 (2011): 307-26.

28. Denise Pan, Gayle Bradbeer and Elaine Jurries, "From Communication to Collaboration: Blogging to Troubleshoot 
E-Resources," Electronic Library 29, no. 3 (2011): 344-53.

29. Kristen Wilson, "Beyond Library Software: New Tools for Electronic Resources Management," Serials Review 37, no. 4 (2011): 294-304.

30. Eric Hartnett and Apryl Price, "iPotential: Mobile Electronic Resource Management on an iPad," Library Collections, Acquisitions \& Technical Services 35, no. 4 (2011): 118-28.

31. David Bindle and Catherine Boden, "Enhancing Gifts-inKind Assessment and Processing with Digital Photography," Collection Building 30, no. 2 (2011): 94-97.

32. Robert Alan et al., "Approval Plan Profile Assessment in Two Large ARL Libraries," Library Resources \& Technical Services 54, no. 2 (2010): 64-76.

33. John S. Brantley, "Approval Plans, Discipline Change, and the Importance of Human Mediated Book Selection," Library Collections, Acquisitions \& Technical Services 34, no. 1 (2010): 11-24.

34. Matthew Buckley and Deborah Tritt, "Ebook Approval Plans: Integrations to Meet User Needs," Computers in Libraries 31, no. 3 (2011): 15-18.

35. Yem Fong et al., "The Alliance Shared Purchase Plan: A New Experiment in Collaborative Collection Development," Technical Services Quarterly 27, no. 1 (2010): 17-38.

36. Gary Handman, "License to Look: Evolving Models for Library Video Acquisition," Library Trends 58, no. 3 (2010): 324-34.

37. Roger L. Cross, "Hunting in the Shadows for Savings: Reevaluating Standing Orders," Bottom Line 23, no. 3 (2010): 90-96.

38. Robert Slater, "Why Aren't E-Books Gaining More Ground in Academic Libraries: E-Book Use and Perceptions: A Review of Published Literature and Research," Journal of Web Librarianship 4, no. 4 (2010): 305-31.

39. Terry Bucknell, "The "Big Deal" Approach to Acquiring E-Books: A Usage Based Study," Serials 23, no. 2 (2010): 126-34.

40. Rebecca Schroeder and Tom Wright, "Electronic Books: A Call for Effective Business Models," New Library World 112, no. 5 (2011): 215-21.

41. Sue Polanka, ed., No Shelf Required: E-books in Libraries (Chicago: ALA, 2011).

42. Sue Polanka, "Purchasing E-Books in Libraries," Library Technology Reports 47, no. 8 (2011): 4-7.

43. David C. Tyler et al., "Just How Right Are the Customers? An Analysis of the Relative Performance of Patron-Initiated Interlibrary Loan Monograph Purchases," Collection Management 35, no. 3/4 (2010): 162-79.

44. Kristine J. Anderson et al., "Liberal Arts Books on Demand: A Decade of Patron-Driven Collection Development, Part 1," Collection Management 35, no. 3/4 (2010): 125-41.

45. Marianne Stowell Bracke, "Science and Technology Books on Demand: A Decade of Patron-Driven Collection Development, Part 2," Collection Management 35, no.3/4 (2010): 142-50.
46. Judith M. Nixon and E. Stewart Saunders, "A Study of Circulation Statistics of Books on Demand: A Decade of PatronDriven Collection Development, Part 3," Collection Management 35, no. 3/4 (2010): 151-61.

47. Dracine Hodges, Cyndi Preston, and Marsh J. Hamilton, "Patron-Initiated Collection Development: Progress of a Paradigm Shift," Collection Management 35, no. 3/4 (2010): 208-21.

48. Erin S. Silva and Cherié Weible, "Own Not Loan: Different Request Sources for Purchase Lists," Collection Management 35, no. 3/4 (2010): 180-84.

49. Uta Hussong-Christian and Kerri Goergen-Doll, "We're Listening: Using Patron Feedback to Assess and Enhance Purchase on Demand," Journal of Interlibrary Loan, Document Delivery \& Electronic Reserve 20, no. 5 (2010): 319-35.

50. Kate Pitcher et al., "Point-of-Need Collection Development: The Getting It System Toolkit (GIST) and a New System for Acquisitions and Interlibrary Loan Integrated Workflow and Collection Development," Collection Management 35, no. 3/4 (2010): 222-36.

51. Kathleen Carlisle Fountain and Linda Frederiksen, "Just Passing Through: Patron-Initiated Collection Development in Northwest Academic Libraries," Collection Management 35, no. 3/4 (2010): 185-95.

52. Gerrit van Dyk, "Interlibrary Loan Purchase-on-Demand: A Misleading Literature," Library Collections, Acquisitions, \& Technical Services 35, no. 2/3 (2011): 83-89.

53. Robert Johnson, "Purchasing Options in Patron-Driven Acquisitions," Against the Grain, 23, no. 3 (2011): 14-16.

54. Melissa De Fino and Mei Ling Lo, "New Roads for PatronDriven E-Books: Collection Development and Technical Services Implications of a Patron-Driven Acquisitions Pilot at Rutgers," Journal of Electronic Resources Librarianship 23, no. 4 (2011): 327-38.

55. Emily McElroy and Susan Hinken, "Pioneering Partnerships: Building a Demand-Driven Consortium eBook Collection," Against the Grain, 23, no. 3 (2011): 34-38.

56. Jason Price, "Patron-Driven Acquisition of Publisher-Hosted Contents: Bypassing DRM," Against the Grain, 23, no. 3 (2011): 16-20.

57. Michael Levine-Clark, "Developing a Multiformat DemandDriven Acquisition Model," Collection Management 35, no.3/4 (2010): 201-7.

58. Douglas Jones, “On-Demand Information Delivery: Integration of Patron-Driven Acquisition into a Comprehensive Information Delivery System," Journal of Library Administration 51, no. 7/8 (2011): 764-76.

59. David A. Swords, ed., Patron-Driven Acquisitions: History and Best Practices (Boston: De Gruyter Saur, 2011).

60. Horava, "Challenges and Possibilities for Collection Management in a Digital Age."

61. Theodore C. Bergstrom, "Librarians and the Terrible Fix: 
Economics of the Big Deal," Serials 23, no. 2 (2010): 77-82.

62. Carmelita Pickett, "Eliminating Administrative Churn: The 'Big Deal' and Database Subscriptions," Serials Review 37, no. 4 (2011): 258-61.

63. Rebecca A. Martin, "Finding Free and Open Access Resources: A Value-Added Service for Patrons," Journal of Interlibrary Loan, Document Delivery \& Electronic Reserve 20, no. 3 (2010): 189-200.
64. Anjana H. Bhatt, "Positioning Your Library in an Open-Access Environment," Journal of Electronic Resources Librarianship 22, no. 3/4 (2010): 96-101.

65. Emma Cryer and Maria Collins, "Incorporating Open Access into Libraries," Serials Review 37, no. 2 (2011): 103-7.

66. E. S. Hellman, "Open Access E-books," Library Technology Reports 47, no. 8 (2011): 18-27. 